\title{
Cigarettes sold in China: design, emissions and metals
}

\author{
Richard J O'Connor, ${ }^{1}$ Oiang Li, ${ }^{2}$ W Edryd Stephens, ${ }^{3}$ David Hammond, ${ }^{4}$ \\ Tara Elton-Marshall, ${ }^{2}$ K Michael Cummings, ${ }^{1}$ Gary A Giovino, ${ }^{5}$ Geoffrey T Fong ${ }^{2,6}$
}

'Department of Health Behavior, Roswell Park Cancer Institute, Buffalo, New York, USA ${ }^{2}$ Department of Psychology, University of Waterloo, Ontario, Canada

${ }^{3}$ School of Geography and Geociences, St Andrews University, Scotland, UK ${ }^{4}$ Department of Health Studies and Gerontology, University of Waterloo, Ontario, Canada ${ }^{5}$ Department of Health Behavior, University at Buffalo, SUNY,

Buffalo, New York, USA

${ }^{6}$ Ontario Institute for Cancer Research, Toronto, Ontario, Canada

\section{Correspondence to}

Dr Richard J O'Connor, Department of Health Behavior, Division of Cancer Prevention and Population Sciences, Roswell Park Cancer Institute, Elm and Carlton Streets, Buffalo, NY 14263, USA; richard. oconnor@roswellpark.org

Received 27 February 2009 Revised 26 June 2009 Accepted 1 July 2009

\section{ABSTRACT}

Background China is the home to the world's largest cigarette maker, China National Tobacco Company (CNTC), yet little is known publicly about the design and emissions of Chinese cigarettes. CNTC is currently in the process of consolidating its brands and has ambitions to export its cigarettes. Machine-measured tar yields of many of its cigarette brands have also been reduced, similar to what occurred in Western countries from the 1970s through the 1990s with so-called 'low-tar' cigarettes introduced to address consumer concerns about health risks from smoking.

Method The current study examines the design and physical characteristics, labelled smoke emissions and tobacco metals content of leading brands of Chinese cigarettes from seven cities purchased in 2005-6 and in 2007.

Results Findings suggest that similar to most countries, tar levels of Chinese cigarettes are predicted primarily by tobacco weight and filter ventilation. Ventilation explained approximately $50 \%$ of variation observed in tar and $60 \%$ variation in carbon monoxide yields. We found little significant change in key design features of cigarettes purchased in both rounds. We observed significant levels of various metals, averaging $0.82 \mu \mathrm{g} / \mathrm{g}$ arsenic (range $0.3-3.3$ ), $3.21 \mu \mathrm{g} / \mathrm{g}$ cadmium (range 2.0-5.4) and $2.65 \mu \mathrm{g} / \mathrm{g}$ lead (range 1.2-6.5) in a subsample of 13 brands in 2005-6, substantially higher than contemporary Canadian products.

Conclusion Results suggest that cigarettes in China increasingly resemble those sold in Western countries, but with tobacco containing higher levels of heavy metals. As CNTC looks to export its product around the world, independent surveillance of tobacco product characteristics, including tobacco blend characteristics, will become increasingly important.

\section{INTRODUCTION}

Approximately $57 \%$ of adult males and $3 \%$ of adult females in China smoke. ${ }^{1}$ The WHO estimates tobacco-related diseases currently kill one million Chinese smokers each year, ${ }^{2}$ with substantial increases expected in the coming years. China is increasingly a target market for multinational tobacco companies given its large population and high smoking rates. ${ }^{3}$ Tobacco Journal International recently pointed to China as '... the only area of the world that the industry can look on with any degree of optimism. ${ }^{4}$ However, multinational brands have yet to gain substantial market share within China. China's domestic market is instead dominated by a state monopoly, and the world's largest tobacco company (by sales volume), the China National Tobacco Company (CNTC), which is overseen by the State Tobacco Monopoly Administration (STMA). Thirty-one independent cigarette factories operate in China under the direction of CNTC and STMA. ${ }^{5}$ STMA has undertaken a plan of modernisation, which includes brand and manufacturing consolidation, aiming to create about 10 large tobacco manufacturing enterprises under CNTC. As part of this modernisation, the number of cigarette brands in China has dropped from 1181 in 2000 to 173 in $2007,{ }^{4}$ further dropping to 154 as of October $2008 .{ }^{6}$ The goal is to create larger brand families with national and potentially international markets as opposed to locally popular varieties. ${ }^{4} 5$

As part of the CNTC modernisation strategy, efforts are under way to reduce tar levels under machine testing. In April 2006, a cap of $15 \mathrm{mg}$ of tar was implemented, with a reported national average machine yield of $13.2 \mathrm{mg}$, as measured by the ISO method. ${ }^{4}$ Lower tar $(<10 \mathrm{mg})$ varieties account for about $2 \%$ of the market, ${ }^{4}$ probably due to a lack of demand and limited competition from foreign brands. ${ }^{7}$ However, the publicly stated goal of the tar level reduction is to reduce harm caused by smoking, 89 which raises the spectre of the low-tar cigarette debacle experienced by Western countries from the 1970s to the 1990s.

Reductions in tar levels to meet the newly adopted $15 \mathrm{mg}$ tar yield ceiling have primarily been achieved through design modification, most prominently increasing filter ventilation, which has the effect of reducing the amount of smoke collected using the ISO machine smoking protocol. It is well established that the ISO regimen is not representative of human smoking patterns and that values obtained from smoking machines cannot be used to distinguish health risks associated with different brands. ${ }^{10-14}$ Nevertheless, tar, nicotine and carbon monoxide emission from the ISO test are required by law to be printed on packs in China. It is increasingly recognised that these numbers are not valid indicators of health risk and can actively mislead consumers. ${ }^{11-13}$ Indeed, Article 11 of the WHO Framework Convention on Tobacco Control (FCTC) has recommended the removal of tar and nicotine numbers from packages. ${ }^{15}$

There are few published reports on the design characteristics of cigarettes sold in China. Chen and colleagues reviewed news reports about herbaltobacco cigarettes in China, which claimed health benefits but for which supporting data were difficult to locate. ${ }^{16}$ Akpan and colleagues ${ }^{17}$ reported the levels of polycyclic aromatic hydrocarbon levels inlocked scheme, see http tobaccocontrol.bmi.com/site/ about/unlocked.xhtml 
in Chinese cigarettes purchased in 2003-4 when smoked under the ISO regimen. Tar yields ranged from $6.3 \mathrm{mg} /$ cigarette to $17.4 \mathrm{mg} /$ cigarette, and benzo[a]pyrene (BaP) levels from $5.8 \mathrm{mg} /$ cigarette to $14.2 \mathrm{ng} /$ cigarette. The reported $\mathrm{BaP}$ levels were 2-7 times higher than contemporary cigarettes from the European Union. But the authors did not report physical characteristics or design features of the tested cigarettes, such as tobacco weight or filter ventilation, which would have a strong influence on observed $\mathrm{BaP}$ levels. Such measurements are critically important for understanding variability in TNCO yields across brands; in particular, filter ventilation can explain virtually all of the interbrand variability in tar levels. ${ }^{18} 19$

In order to better understand the emerging epidemic of tobacco-caused illness in China and globally, given CNTC's role as the largest producer of cigarettes in the world, data on the changing design and emission characteristics of Chinese cigarettes are needed (eg, Geoffrey T, Fong, Yuan Jiang, et al. Introduction to the International Tobacco Control Policy Evaluation Project in China (ITC China Project). Tobacco Control, unpublished). This paper presents data on the physical characteristics, tobacco contents and selected smoke emissions of popular cigarette brands manufactured and sold in seven cities in China during 2005-6 and 2007. We addressed two main research questions: (1) how do the design and emission characteristics of Chinese cigarettes compare to those of established international brands; and (2) to what extent did the design and emission characteristics of Chinese cigarettes change between 2005-6 and 2007, if at all?

\section{METHODS}

Data for this study come from cigarettes purchased in China initially from December 2005 to March 2006 (2005-6), and again in October-December 2007 (2007). Cigarettes were purchased at typical retail locations in seven cities in China (Beijing, Changsha, Guangzhou, Shanghai, Shenyang, Yinchuan, Zhengzhou). In each city, a list of target brands was created and one carton of each brand was purchased at each of three distinct retail locations. In 2006, 65 target domestic brands were identified from local investigator knowledge of popular brands available at retail. In 2007, 28 leading domestic brands were identified by self-report data obtained from Wave 1 of the ITC China Survey. ${ }^{20}$ While some imported varieties were also purchased (eg, Marlboro, State Express 555, Mild Seven), the current discussion focuses on domestic cigarette varieties. The tested brand varieties are listed in table 1 . All cigarettes were shipped to the Tobacco Research Laboratory at Roswell Park Cancer Institute (RPCI) via overnight courier and stored unopened at $-20^{\circ} \mathrm{C}$ until analysis.

\section{Characteristics}

Cigarette physical and design characteristics were assessed on all products using methods described previously. ${ }^{18} 19$ Prior to analysis, the cigarettes tested were stored in a freezer at $-20^{\circ} \mathrm{C}$. The packs were conditioned for a minimum of 48 hours at $22^{\circ} \mathrm{C} \pm 2.0^{\circ} \mathrm{C}$ and $60 \% \pm 2.0 \%$ relative humidity in an environmental chamber per ISO. For a single brand, five cigarettes were randomly selected for each assay and the data averaged together. Physical measures were taken using digital callipers, including cigarette length and diameter, filter length, length of the tipping paper, distance to any areas of filter ventilation and the length of the tobacco rod. Filter weight measurements were made using a Mettler-Toledo analytical balance. The moisture and weight of tobacco was then analysed using an HR83 Moisture Analyser (Mettler-Toledo, Ohio, USA). The moisture content was determined as the percentage change in weight after heating the tobacco from five cigarettes with a halogen bulb at $125^{\circ} \mathrm{C}$ until an asymptote was reached. Weight is reported as the average of tobacco from five cigarettes prior to drying. The level of permeability of each cigarette paper was also examined using a PPM1000M paper porosity device (Cerulean, Milton-Keynes, UK) using the vacuum method. Lastly, the measurements of the cigarette filter ventilation and pressure drop were taken using a KC3 combined dilution/pressure drop instrument (BorgwaldtKC, Richmond, Virginia, USA). For consistency, all products were tested contemporaneously and laboratory analysis was completed in April 2009.

\section{Emissions}

Values of tar, nicotine and $\mathrm{CO}$ (where available) as reported on packs were recorded for all products. These are ostensibly measured using the ISO testing regimen (ISO 3308), ${ }^{\mathrm{i}}$ in which $35 \mathrm{ml}$ puffs of 2-second duration are drawn from the cigarette every 60 seconds until a fixed butt length is reached.

\section{Metals concentration}

A randomly selected subsample of 2006 brands $(n=13)$ was tested for trace metals in unburned tobacco using polarised energy dispersive x-ray fluorescence ${ }^{21}$ at St Andrews University in October-November 2007. In brief, tobacco extracted from about 20 cigarettes was dried and powdered. Two pressed pellets, each of about $6 \mathrm{~g}$, were analysed quantitatively for several heavy metals and other trace elements on a Spectro XLAB using calibrations based on a wide range of reference standards including foliage materials. A more complete description with data on detection limits, etc, is published elsewhere. ${ }^{22}$

\section{Statistical analysis}

Analysis of data was conducted using SPSS 14.0. Brands that were not repeatedly sampled in each year were compared by Mann-Whitney $U$ tests to account for differences in variance between samples. Repeatedly sampled brands $(n=15)$ were compared via Wilcoxon signed rank tests. Averages of tested Chinese brands were compared to previously published data using $t$ tests based on means and standard deviations. Relations between measured physical and design parameters and TNCO emissions were examined via stepwise linear regression, with an indicator variable for year of purchase was forced first into the model. Stepwise entry of other potential predictors used $p$ value criteria of 0.10 and 0.15 for entry and removal, respectively, to be inclusive of features that might have small overall roles.

\section{RESULTS}

\section{Product characteristics}

Table 1 presents the per-brand values for ventilation, paper permeability, tobacco weight and rod and filter densities. Mean values for the products purchased in each year are presented in table 2. Comparing those brands purchased at both rounds $(n=15)$ very few significant differences are evident. The 2007 versions of these products were slightly longer (apparently mostly attributed to longer tobacco rods), and had slightly higher packing density, but slightly lower moisture content.

Table 3 presents comparisons of the Chinese market cigarettes (combining both sets, but including only the 2007 purchase of repeated brands) to two published sources of cigarette characteristics data. The study by O'Connor and colleagues ${ }^{19}$

i http://www.iso.org/iso/iso_catalogue/catalogue_ics/catalogue_detail_ics.htm? csnumber $=28325$. 
Table 1 Chinese brands examined in the current study with selected physical and design characteristics reported, 2005-7

\begin{tabular}{|c|c|c|c|c|c|c|c|}
\hline Brand & Descriptor & UPC & $\begin{array}{l}\text { Tobacco } \\
\text { weight (mg) }\end{array}$ & $\begin{array}{l}\text { Filter density } \\
(\mathrm{mg} / \mathrm{ml})\end{array}$ & $\begin{array}{l}\text { Rod density } \\
\text { (mg/ml) }\end{array}$ & $\begin{array}{l}\text { Paper permeability } \\
\text { (CORESTA) }\end{array}$ & $\begin{array}{l}\text { Ventilation } \\
(\%)\end{array}$ \\
\hline Baisha & Blue & 191098 & 660.4 & 109.2 & 251.5 & 53.6 & 0.0 \\
\hline Baisha & Combination & 191838 & 693.4 & 116.9 & 258.5 & 52.0 & 0.0 \\
\hline Baisha & Red, soft, treasure & 192545 & 693.4 & 116.7 & 263.3 & 50.8 & 0.0 \\
\hline Baisha & Silver lid & 191500 & 690.6 & 111.8 & 240.2 & 52.0 & 0.0 \\
\hline Baisha & White lid & 191029 & 714.2 & 113.8 & 244.9 & 34.9 & 0.0 \\
\hline Cocopalm & Blue & 002097 & 693.2 & 114.9 & 235.6 & 47.9 & 2.0 \\
\hline Cocopalm & Green & 002752 & 676.4 & 116.4 & 229.7 & 47.1 & 0.1 \\
\hline Cocopalm & Red & 002233 & 715.0 & 114.0 & 255.4 & 78.5 & 2.5 \\
\hline Daqianmen & Soft pack & 075916 & 728.6 & 117.2 & 248.0 & 55.8 & 3.9 \\
\hline Derby & King size, tan & 132268 & 676.8 & 118.9 & 236.5 & 57.2 & 22.1 \\
\hline Derby & White, soft pack & 126021 & 669.2 & 117.8 & 256.7 & 45.9 & 0.0 \\
\hline Double happiness & Low tar & 075824 & 726.8 & 107.1 & 250.1 & 52.8 & 20.7 \\
\hline Double happiness & Regular & 075800 & 737.8 & 117.9 & 243.1 & 51.6 & 2.8 \\
\hline Double happiness & Soft & 075817 & 730.4 & 113.1 & 237.9 & 57.3 & 3.6 \\
\hline Double happiness & Super aromatic & 75831 & 633.0 & 114.3 & 230.4 & 57.4 & 23.5 \\
\hline Furong Xiangyan & Soft, gold & 199414 & 699.6 & 121.0 & 244.9 & 38.1 & 2.2 \\
\hline Furongwang & Masterwork & 193856 & 660.4 & 84.3 & 255.6 & 52.2 & 0.1 \\
\hline Furongwang & Yellow, lid & 193498 & 729.0 & 122.3 & 248.8 & 52.6 & 0.9 \\
\hline Golden leaf & Light of the century & 161145 & 693.8 & 112.2 & 239.8 & 43.2 & 0.1 \\
\hline Good fortune & Light red & 050371 & 634.2 & 112.8 & 237.1 & 51.5 & 0.3 \\
\hline Happiness & King size, red & 050678 & 698.6 & 119.5 & 246.9 & 54.5 & 1.7 \\
\hline Hatamen & Aromatic & 149358 & 666.8 & 106.9 & 244.8 & 68.6 & 3.4 \\
\hline Hongqiqu & Gold elite & 164511 & 661.4 & 109.5 & 248.4 & 64.8 & 0.8 \\
\hline Hongqiqu & Light of the milkyway & 164542 & 645.4 & 118.2 & 246.4 & 55.1 & 14.2 \\
\hline Hongqiqu & Silver, special 1st class & 164375 & 639.8 & 111.8 & 239.2 & 64.3 & 0.9 \\
\hline Hongtashan & Gold & 314015 & 676.6 & 117.1 & 246.7 & 37.5 & 32.6 \\
\hline Hongtashan & Red platinum & 317450 & 688.2 & 111.9 & 247.4 & 59.6 & 18.5 \\
\hline Hongtashan & Regular, red & 316156 & 666.8 & 110.9 & 242.7 & 38.3 & 13.3 \\
\hline Hongtashan & Yellow & 048231 & 687.2 & 113.8 & 253.6 & 37.2 & 29.3 \\
\hline Houwang & Hard & 058032 & 668.4 & 114.1 & 252.3 & 57.1 & 1.0 \\
\hline Jinmanggou & Green & 166041 & 661.6 & 116.9 & 252.3 & 67.5 & 0.0 \\
\hline Jinxuchang & Yellow soft & 162012 & 685.4 & 110.3 & 227.4 & 46.5 & 1.2 \\
\hline LanLing & Green & 091794 & 670.8 & 118.4 & 257.7 & 40.5 & 0.2 \\
\hline LanLing & Yellow & 091176 & 691.8 & 112.8 & 248.2 & 54.1 & 1.5 \\
\hline Lesser Panda & Black soft & 337168 & 720.6 & 112.4 & 245.7 & 53.5 & 16.6 \\
\hline Liqun & Hard & 118170 & 711.4 & 119.2 & 252.9 & 56.4 & 2.8 \\
\hline Liqun & Long filter & 118811 & 583.4 & 111.1 & 225.9 & 45.8 & 0.0 \\
\hline Mellow Furong & Yellow & 193818 & 684.2 & 113.6 & 233.3 & 39.1 & 0.0 \\
\hline Peony & Filter kings- red & 075855 & 665.6 & 112.2 & 225.5 & 56.7 & 5.8 \\
\hline Peony & Red & 075589 & 698.6 & 115.6 & 229.1 & 61.7 & 0.4 \\
\hline Peony & Red, soft pack & 075862 & 710.2 & 119.2 & 261.8 & 61.1 & 4.0 \\
\hline Peony & White & 076012 & 714.6 & 117.9 & 242.2 & 58.0 & 4.3 \\
\hline Pingtan & Red & 069427 & 655.2 & 113.1 & 238.7 & 53.7 & 0.1 \\
\hline Pingtanxian Gyan & White & 069205 & 700.2 & 120.2 & 259.7 & 62.0 & 0.5 \\
\hline Pride & Black, multi-coloured print & 025577 & 729.4 & 104.9 & 258.2 & 56.9 & 0.4 \\
\hline Sanhua & Blue & 160018 & 668.6 & 111.0 & 218.2 & 39.9 & 1.0 \\
\hline
\end{tabular}


Table 1 Continued

\begin{tabular}{|c|c|c|c|c|c|c|c|}
\hline Brand & Descriptor & UPC & $\begin{array}{l}\text { Tobacco } \\
\text { weight (mg) }\end{array}$ & $\begin{array}{l}\text { Filter density } \\
(\mathrm{mg} / \mathrm{ml})\end{array}$ & $\begin{array}{l}\text { Rod density } \\
\text { (mg/ml) }\end{array}$ & $\begin{array}{l}\text { Paper permeability } \\
\text { (CORESTA) }\end{array}$ & $\begin{array}{l}\text { Ventilation } \\
(\%)\end{array}$ \\
\hline Shuangxi & Classic hard pack & 000642 & 690.6 & 117.9 & 239.3 & 41.9 & 0.5 \\
\hline Shuangxi & Soft pack & 001489 & 698.2 & 114.9 & 228.2 & 48.7 & 1.1 \\
\hline State Guests & Black, lights & 052504 & 719.2 & 113.0 & 250.3 & 55.3 & 0.3 \\
\hline Stone Forest & White & 050883 & 656.2 & 120.3 & 235.1 & 48.8 & 1.3 \\
\hline The Scarlet Camellia & Purple & 310192 & 738.0 & 122.3 & 257.3 & 74.6 & 0.3 \\
\hline The Scarlet Camellia & Red & 045605 & 728.6 & 125.3 & 256.0 & 63.0 & 0.7 \\
\hline Yizhibi & Hard & 149396 & 688.0 & 102.6 & 248.0 & 62.5 & 0.9 \\
\hline Yun Yan & Regular (purple) & 046886 & 647.6 & 119.2 & 243.2 & 58.4 & 0.6 \\
\hline Yun Yan & Regular (white) & 045636 & 649.2 & 117.2 & 236.5 & 68.4 & 1.1 \\
\hline Yun Yan & Regular, red & 045575 & 705.8 & 113.7 & 239.0 & 67.4 & 1.6 \\
\hline Yun Yan & Treasure & 045902 & 713.6 & 114.6 & 238.1 & 61.1 & 0.2 \\
\hline Zhongnanhai & Herb Blend Regular ${ }^{10}$ & 071284 & 648.4 & 109.9 & 210.8 & 60.0 & 27.8 \\
\hline Zhongnanhai & Herb Blend- Regular ${ }^{8}$ & 071499 & 600.0 & 114.9 & 218.8 & 56.4 & 26.5 \\
\hline Zhongnanhai & Red, regular, hard & 072038 & 722.0 & 114.2 & 238.9 & 52.2 & 11.8 \\
\hline Zhongnanhai & White, hard $^{3}$ & 071673 & 591.2 & 117.8 & 216.8 & 58.3 & 59.2 \\
\hline Zhongnanhai & White, hard, colourful ${ }^{8}$ & 071765 & 577.2 & 109.9 & 208.5 & 57.0 & 25.0 \\
\hline
\end{tabular}

examined characteristics of cigarettes sold in the USA, UK, Canada and Australia in 2005, while the study by Counts and colleagues $^{23}$ reported limited design information on Philip Morris international brands in 2004. As one can see the Chinese cigarettes are substantially different on a number of parameters, most notably filter ventilation, but also rod length, tobacco weight, rod and filter density, and paper permeability.

\section{TNCO emissions and design}

We examined the relation of the measured design features to labelled emissions of tar, nicotine and $\mathrm{CO}$ in the 78 unique varieties of Chinese cigarettes using stepwise linear regression. Results are shown in table 4. Prediction of tar yields involved a number of parameters, with ventilation making the largest single contribution to variation in yields (over $57 \%$ of variance), and parameters such as filter weight and paper permeability making minor contributions. The total model had an adjusted $\mathrm{R}^{2}$ of 0.721 , suggesting that the majority of variation in tar could be explained by the included parameters. Nicotine yielded a less complex model, with ventilation again serving as the largest predictor ( $40 \%$ of variance), with tobacco weight and filter length serving as significant contributors. However, the overall adjusted $R^{2}$ for this model was 0.472 , suggesting that half the variation in nicotine yields could be explained by unmeasured parameters. Finally, for $\mathrm{CO}$, the major contributors were ventilation and paper permeability, together explaining $49.3 \%$ of variation in $\mathrm{CO}$ yields. Design features not listed did not contribute significantly to the respective prediction model ( $\mathrm{p}$ values $>0.20$ )

\section{Metals in unburned tobacco}

Overall, as depicted in figure 1, the levels of metals of health concern $(\mathrm{Cr}, \mathrm{As}, \mathrm{Cd}, \mathrm{Pb})$ varied considerably among brands. The tested Chinese brands averaged $0.55 \mu \mathrm{g} / \mathrm{g}$ Cr (range 0.0-1.0), $0.78 \mu \mathrm{g} / \mathrm{g}$ As (range 0.3-3.3), $3.24 \mu \mathrm{g} / \mathrm{g}$ Cd (range 2.0-5.4) and $2.54 \mu \mathrm{g} / \mathrm{g} \mathrm{Pb}$ (range 1.2-6.5). figure 2 presents comparison data from the Canadian market in 2004 (see Hammond and $\mathrm{O}^{\prime}$ Connor for more details ${ }^{24}$ ) indicating that levels of $\mathrm{Cr}$ are comparable to Canadian brands (though statistically significantly different, $p$ values $<0.02$ by $t$ test), but that levels of As, $\mathrm{Cd}$ and $\mathrm{Pb}$ are substantially (2-3-fold) higher ( $\mathrm{p}$ values $<0.0001)$

Table 2 Mean physical characteristics of Chinese brands tested in both 2005-6 and 2007

\begin{tabular}{|c|c|c|c|c|}
\hline & \multicolumn{2}{|c|}{ Independent samples } & \multicolumn{2}{|c|}{ Repeat samples $(n=15)$} \\
\hline & \multicolumn{2}{|l|}{ Mean (SE) } & \multicolumn{2}{|c|}{ Mean (SE) } \\
\hline & $2005-6(n=50)$ & $2007(n=13)$ & $2005-6$ & 2007 \\
\hline Labelled nicotine (mg/cigarette) & $1.13(0.02)$ & $1.12(0.04)$ & $1.07(0.04)$ & $1.08(0.04)$ \\
\hline Labelled COキ (mg/cigarette) & $13.4(0.55)$ & $13.8(0.55)$ & $12.9(0.5)$ & $12.9(0.4)$ \\
\hline Cigarette length $(\mathrm{mm})$ & $83.8(0.02)$ & $83.7(0.04)$ & $83.6(0.06)$ & $83.9 \neq(0.03)$ \\
\hline Tobacco rod length (mm) & $61.4(0.40)$ & $62.3(0.62)$ & $61.4(0.66)$ & $62.4 \neq(0.63)$ \\
\hline Filter length (mm) & $22.0(0.54)$ & $20.2^{*}(1.1)$ & $22.0(0.64)$ & $21.8(0.67)$ \\
\hline Filter weight (mg) & $115.8(2.68)$ & $107.3(6.2)$ & $114.6(4.7)$ & $114.6(3.1)$ \\
\hline Paper permeability (CORESTA units) & $52.7(1.40)$ & $52.3(1.88)$ & $49.5(0.70)$ & $52.9(0.90)$ \\
\hline Pressure drop (mmwg) & $107.0(1.61)$ & $115.9 *(2.74)$ & $119.0(3.2)$ & $112.9(2.6)$ \\
\hline Ventilation $(\%)$ & $7.3(1.67)$ & $4.9(2.74)$ & $5.9(2.0)$ & $4.6(1.8)$ \\
\hline
\end{tabular}


Table 3 Mean (SD) of physical characteristics of cigarettes from different studies

\begin{tabular}{|c|c|c|c|c|c|c|}
\hline \multirow[b]{2}{*}{ Parameter } & \multicolumn{2}{|c|}{$\begin{array}{l}\text { China (current } \\
\text { study) }\end{array}$} & \multicolumn{2}{|c|}{$\begin{array}{l}\text { O'Connor et al } \\
(2008)^{18}\end{array}$} & \multicolumn{2}{|c|}{$\begin{array}{l}\text { Counts et al } \\
(2005)^{22}\end{array}$} \\
\hline & Mean & SD & Mean & SD & Mean & SD \\
\hline No tested & 78 & & 172 & & 48 & \\
\hline Pressure drop & $109.6^{*}$ & 11.4 & 98.6 & 15.3 & NR & \\
\hline Ventilation & $6.4^{*} \dagger$ & 10.7 & 37.8 & 21.6 & 37.3 & 22.1 \\
\hline $\begin{array}{l}\text { Tobacco rod } \\
\text { length }\end{array}$ & $61.7^{*}$ & 2.6 & 59.9 & 3.3 & $\mathrm{NR}$ & \\
\hline $\begin{array}{l}\text { Tipping paper } \\
\text { length }\end{array}$ & 28.9 & 2.6 & 28.2 & 3.1 & NR & \\
\hline Tobacco weight & $683.3^{*}$ & 36.9 & 640.0 & 79.1 & 679.0 & 86.8 \\
\hline Rod density & $243.2^{*}$ & 11.7 & 229.1 & 23.7 & NR & \\
\hline Filter density & $114.2^{*}$ & 5.3 & 122.2 & 10.9 & NR & \\
\hline $\begin{array}{l}\text { Paper } \\
\text { permeability }\end{array}$ & $53.3 \dagger$ & 9.6 & NR & & 45.0 & 16.5 \\
\hline
\end{tabular}

* significantly different from 0 'Connor et $a l^{18}$ at $\mathrm{p}<0.0001$ by $\mathrm{t}$ test.

$\dagger$ significantly different from Counts et $a l^{22}$ at $p<0.001$ by $t$ test.

NR, not reported.

\section{DISCUSSION}

The current paper examined the variation in design features in contemporary Chinese cigarettes and their relation to reported ISO emissions, as well as tobacco metal contents in a subsample of popular cigarette brands purchased in seven cities in China in 2005-6 and 2007. The physical and design characteristics of Chinese domestic cigarettes were broadly similar to manufactured cigarettes examined in international samples. ${ }^{19} 23 \quad 25$ However, they did show significant differences in specific parameters such as ventilation, tobacco weight and paper permeability. Mass-manufactured cigarettes have relatively tight parameters for features such as overall length and diameter, such that there is little variation among brands or across countries within a product class (eg, king size filter tipped). Most observed

Table 4 Stepwise linear regression results for tar, nicotine, and carbon monoxide on cigarettes purchases in China, 2005-7 $(n=78)$

\begin{tabular}{|c|c|c|c|c|c|}
\hline Variable & $\Delta R^{2}$ & B & Beta & $\mathbf{t}$ & p Value \\
\hline \multicolumn{6}{|l|}{ Tar } \\
\hline Intercept & & -4.183 & & -0.796 & 0.429 \\
\hline Year & 0.049 & -1.274 & -0.283 & -4.455 & $<0.001$ \\
\hline Ventilation & 0.577 & -0.118 & -0.584 & -7.675 & $<0.001$ \\
\hline Tobacco weight & 0.047 & 8.785 & 0.149 & 1.615 & 0.111 \\
\hline Filter weight & 0.044 & 39.023 & 0.332 & 3.522 & 0.001 \\
\hline Paper permeability & 0.016 & -0.25 & -0.112 & -1.791 & 0.078 \\
\hline Rod length & 0.010 & 0.160 & 0.192 & 1.683 & 0.097 \\
\hline Final model & 0.721 & & & & \\
\hline \multicolumn{6}{|l|}{ Nicotine } \\
\hline Intercept & & 0.095 & & 0.299 & 0.766 \\
\hline Year & 0.008 & -0.033 & -0.098 & -1.142 & 0.257 \\
\hline Ventilation & 0.402 & -0.007 & -0.441 & -4.351 & $<0.001$ \\
\hline Tobacco weight & 0.037 & 1.195 & 0.275 & 3.064 & 0.003 \\
\hline Filter length & 0.053 & 0.012 & 0.277 & 2.778 & 0.007 \\
\hline Final model & 0.472 & & & & \\
\hline \multicolumn{6}{|l|}{$\mathrm{CO}(\mathrm{N}=40)$} \\
\hline Intercept & & 16.571 & & 14.669 & $<0.001$ \\
\hline Year & 0.004 & -0.183 & -0.049 & -0.429 & 0.67 \\
\hline Ventilation & 0.477 & -0.142 & -0.713 & -6.244 & $<0.001$ \\
\hline Paper permeability & 0.050 & -0.040 & -0.224 & -1.988 & 0.054 \\
\hline Final model & 0.493 & & & & \\
\hline
\end{tabular}

$\mathrm{B}$, unstandardised regression weight.

Beta, standardised regression weight. brand-to-brand variation occurs in tobacco and filter weight, filter length, paper permeability and filter ventilation. Consistent with data from other countries, filter ventilation emerged as the most important predictor of labelled tar, nicotine and $\mathrm{CO}$ yields, though the relation was not as strong as observed in other studies, where $\mathrm{R}^{2}$ values of 0.90 and greater are seen. ${ }^{18} 19$ Differences in predicted yields from previous studies probably reflect the restricted range of yields examined in China since very few brands purchased had tar yields lower than $10 \mathrm{mg}$, in contrast to many Western markets where $50 \%$ or more of tar yields fall below $10 \mathrm{mg}$. The predictive model for nicotine was weakest, suggesting that engineering features may not be the primary drivers of nicotine yield in China, especially considering the very narrow range of yields observed. The findings overall underscore the influence of ventilation, even at relatively low levels, in manipulating the emission levels of products when tested under the standard ISO regimen, which remains the basis for reporting in much of the world. The fact that few brands on the Chinese market currently have yields below $10 \mathrm{mg}$ suggests a potential marketing opportunity for CNTC as Chinese smokers become increasingly educated about the health risks of smoking. Indeed, evidence from the ITC Survey suggests that many Chinese smokers believe 'light'/'low tar' cigarettes are less harmful. $^{25}$

We found relatively high levels of arsenic, lead and cadmium in the tobacco of domestic Chinese cigarettes, substantially higher than cigarettes from Canada. ${ }^{26}$ This is consistent with existing literature on metals in counterfeit cigarettes, the majority of which appear to originate in China. ${ }^{21}$ Metal content in tobacco leaf primarily is driven by the metal content of the soil in which it is grown, rather than resulting from processing. ${ }^{27}$ Various investigations using different methodologies consistently indicate that cadmium (an IARC Type 1 carcinogen) transfers linearly from tobacco into smoke emissions. ${ }^{2428} 29$ Galazyn-Sidorczuk et al ${ }^{28}$ have shown that this correlation extends to blood cadmium levels. Recent work also suggests that cadmium and lead levels are higher in lung tissues of current and former smoking lung cancer patients relative to non-smokers. ${ }^{30}$ Furthermore, large increases in transference factors are observed using the Canadian intense smoking protocol compared with the ISO protocol (factors of 2.9 and 2.4 respectively for $\mathrm{Cd}$ and $\mathrm{Pb}$; 25), meaning transfer increases with increasing smoking intensity. Thus cadmium and lead concentrations in tobacco can be taken as first order indicators of relative exposure to different products. While the relative health burden of metal exposure from tobacco is still unclear, some studies suggest that they might be at least as important in carcinogenesis as polycyclic aromatic hydrocarbons (PAHs) and N-nitrosamines. ${ }^{31}$

The higher yields of cadmium and lead in cigarettes manufactured in China are worrisome given current smoking prevalence in China and CNTC's export ambitions. Health and regulatory officials around the world should be concerned about the potential for export of cigarettes (or processed tobacco) with manifold higher contents of known toxicants from China into international markets. From a regulatory perspective, precluding import of tobacco and tobacco products with high arsenic, cadmium, and/or lead content, using relatively simple leaf and filler analysis as screening tools, could have substantial impacts on the international tobacco trade and, potentially, public health. Regulatory limits on metal contamination would not be unprecedented. Australia and New Zealand, for example, have maximal limits for arsenic (1 mg/ $\mathrm{kg}^{\mathrm{ii}}$ in cereals), cadmium $(0.1 \mathrm{mg} / \mathrm{kg}$ in leafy vegetables $)$ and lead $(0.1 \mathrm{mg} / \mathrm{kg}$ in

\footnotetext{
ii $1 \mathrm{mg} / \mathrm{kg}=1 \mathrm{ug} / \mathrm{g}$.
} 
Figure 1 Distribution of metal content of unburned tobacco in 13 Chinese cigarette varieties, 2005-6.

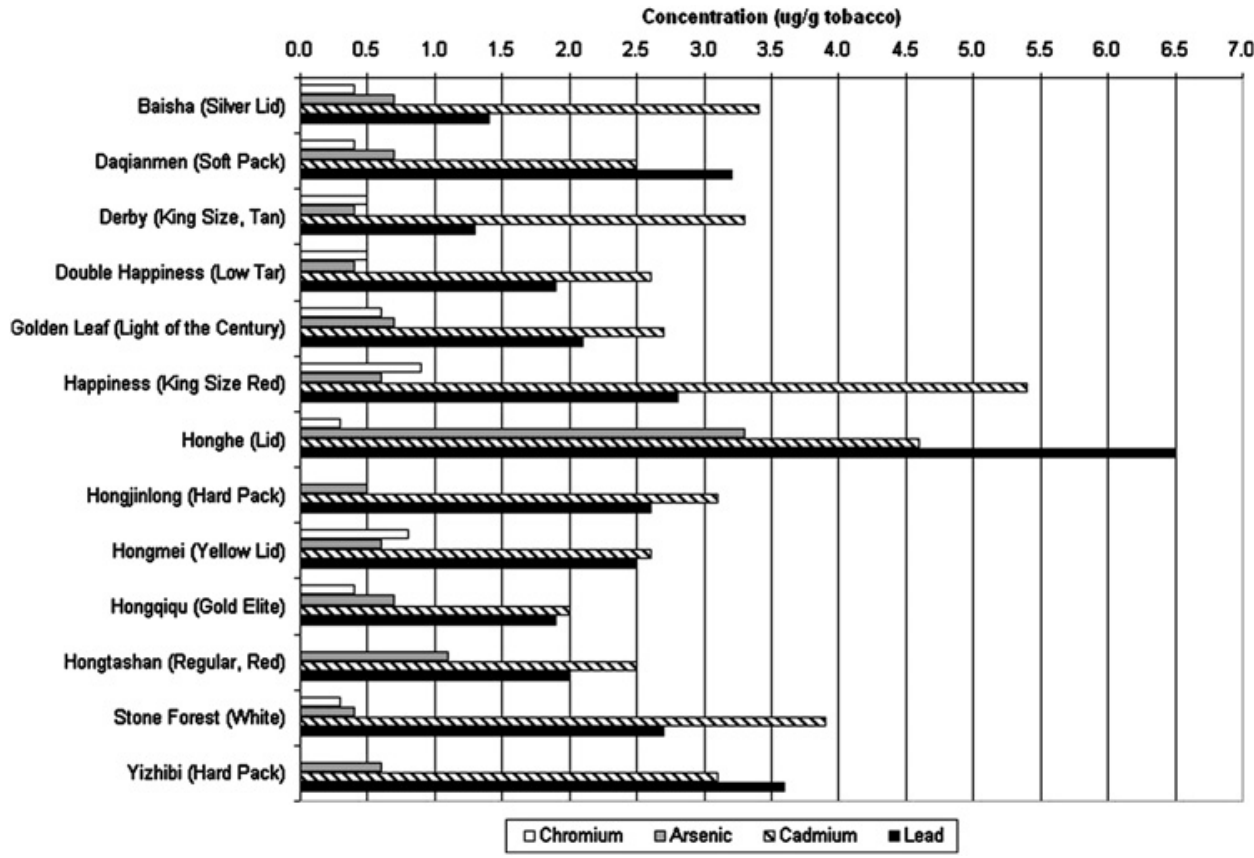

vegetables) in plant products intended as foods. ${ }^{32}$ Cigarette tobacco (even those in Canada) generally exceeds these levels.

A limitation of the current study is the reliance on labelled values for tar, nicotine and $\mathrm{CO}$ for regression analyses rather than direct testing of emissions. In addition, metals were only tested for a subset of brands. Another limitation is that brands for this study were not selected strictly on the basis of market share or to represent a broad range of tar yields, but rather were a convenience sample. Future research should replicate these findings across a market-based sample.

China is a party to the FCTC and is moving to implement regulations to meet its treaty obligations. Simultaneously, it owns the world's largest tobacco company. Chinese tobacco scientists appear to be active in research and development of new products and emission reduction technologies, which speaks to the growing sophistication of the Chinese industry. ${ }^{33}$ These reports are consistent with STMA's moves to modernise factories and adopt manufacturing and quality control technologies from the major international companies. It is also possible, then, that product-level regulations such as chemicalspecific emissions limits ${ }^{12}$ could be implemented in China with emerging production technologies. Particular attention should be paid to eliminating heavy metals from tobacco.

Overall, the findings from this study suggest that Chinese cigarettes differ in substantive ways from cigarettes sold in Western markets, though they follow similar patterns in determining tar and nicotine yields under standard testing conditions. But the presence of high levels of heavy metals in Chinese cigarettes may constitute a potential global public health problem as exports of Chinese cigarettes continue to increase.
Figure 2 Comparisons of average metal contents for Chinese and Canadian cigarettes. Error bars represent $95 \%$ Cls.

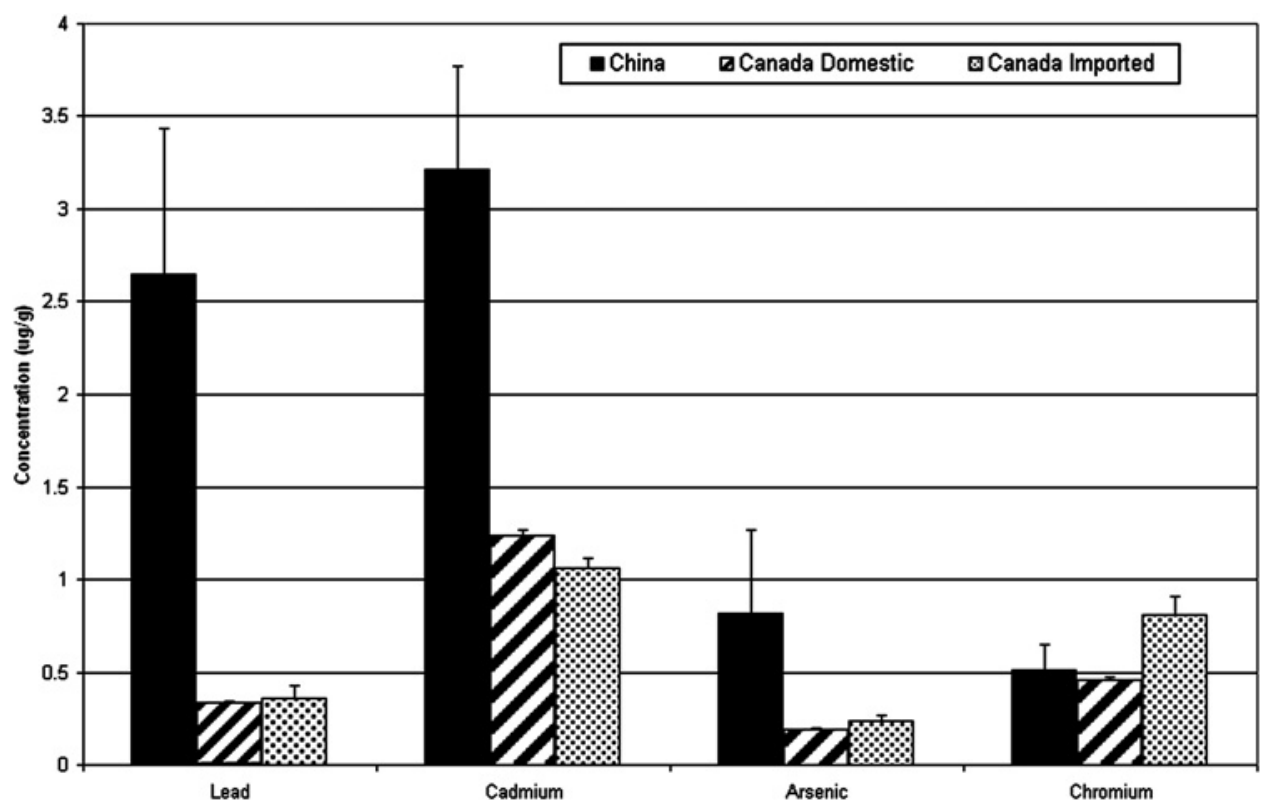




\section{What this paper adds}

There is very limited public information about the design and emissions of Chinese cigarettes. In recent years the China National Tobacco Company (CNTC) has reduced the machine measured tar yields of many of its cigarette brands, similar to what occurred in Western countries from the 1970s through the 1990s with so-called 'low-tar' cigarettes introduced to address consumer concerns about health risks from smoking. Findings from this study suggest that, as in most countries, reported tar levels are predicted primarily by tobacco weight and filter ventilation. We found particularly high levels of cadmium and lead in Chinese cigarette tobacco, which is probably the result of soil conditions where tobacco is grown in China. The presence of high levels of these and other heavy metals may constitute a global health concern as China increases their cigarette exports.

Regulators should require disclosure of the source and growing conditions of tobacco used in all products and should consider product standards based on heavy metal content.

Acknowledgements The authors thank Rosalie Caruso for editorial and analysis assistance and Kimberly Wilkins, Angus Calder, Jessica Palmer and Tammy Vance for their product analysis work.

Funding Funding This work was supported by the US National Cancer Institute via the Roswell Park Cancer Institute Transdisciplinary Tobacco Use Research Center (P50CA111236) and by R01CA125116. Additional support was provided by the Canadian Institutes of Health Research (79551) and by the Ontario Institute for Cancer Research.

Competing interests RJO has served as a consultant to the US Food and Drug Administration Tobacco Products Scientific Advisory Committee (Tobacco Constituents subcommittee). KMC has provided expert testimony on behalf of plaintiffs in cases against tobacco companies.

Patient consent Obtained.

Provenance and peer review Not commissioned; externally peer reviewed.

\section{REFERENCES}

1. World Health Organization. Report on the global tobacco epidemic, 2008: The MPOWER package. Geneva, Switzerland: World Health Organization, 2008a. http:// www.who.int/tobacco/mpower/mpower report full 2008.pdf (accessed Jun 2008).

2. World Health Organization. Towards a tobacco-free China. Geneva, Switzerland: World Health Organization, 2007. http://www.wpro.who.int/china/sites/tfi/ (accessed Aug 2007).

3. Mackay J, Eriksen M, Shafey 0. The tobacco atlas, 2nd edn. Atlanta, Georgia: American Cancer Society, 2006:1-128.

4. Glogan T. China: still a mecca for the tobacco industry. Tob J Int, 2008. http://www. tobaccojournal.com/China_Still_a_Mecca_for_the_tobacco_industry.48796.0. html (accessed Feb 2008).

5. Gay G. Still elusive; For the foreseeable future, China's much-hyped potential will remain just that. Tobacco Reporter 2007:34-8.

6. STMA Official s Continued Reduction of Existing Cigarette Brands, 2008. http://act. tobaccochina.net/englishnew/content1.aspx?id=37336 (accessed Feb 2009).

7. Euromonitor International. The world market for tobacco, 2004. http://www. euromonitor.com/The World Market for Tobacco (purchase required) (accessed Feb 2009).
8. China's Tobacco Industry Aims at Lower Tar Level. 2002. http://english.peopledaily. com.cn/200201/14/eng20020114 88647.shtml (accessed February 2009).

9. Tar content of Chinese brand cigarettes continues to fall. China Daily/Xinhua 2008 http://english.people.com.cn/90001/90776/6339198.html (accessed 27 Feb 2009).

10. National Cancer Institute. The FTC cigarette test method for determining tar, nicotine, and carbon monoxide yields of US cigarettes. Smoking and Tobacco Control Monograph 7. Bethesda: NCl, 1996

11. National Cancer Institute. Risks associated with smoking cigarettes with low machine-measured yields of tar and nicotine. Smoking and Tobacco Control Monograph 13. Bethesda: NCl, 2001.

12. Burns DM, Dybing E, Gray N, et al. Mandated lowering of toxicants in cigarette smoke: a description of the WHO TobReg proposal. Tob Control 2008;17: 132-41.

13. FTC dumps test for cigarette tar, nicotine. Reuters 2008. Available at http://www. reuters.com/article/domesticNews/idUSTRE4AP7VP20081126.

14. Hammond D, Fong GT, Cummings KM, et al. Cigarette yields and human exposure: a comparison of alternative testing regimens. Cancer Epidemiol Biomarkers Prev 2006;15:1495-501.

15. First Report of Committee A (Draft). Conference of the Parties to the WHO Framework Convention on Tobacco Control. Third Session, Durban, South Africa, 2008. http://www.tobaccolabels.ca/fctcandh/fctcarticl (accessed Feb 2009).

16. Chen A, Glantz S, Tong E. Asian herbal-tobacco cigarettes: "not medicine but less harmful"? Tob Control 2007;16:e3.

17. Akpan V, Huang S, Lodovici M, et al. High levels of carcinogenic polycyclic aromatic hydrocarbons (PAH) in 20 brands of Chinese cigarettes. J Appl Toxicol 2006;26:480-3.

18. Kozlowski LT, Mehta NY, Sweeney CT, et al. Filter ventilation and nicotine conten of tobacco in cigarettes from Canada, the United Kingdom, and the United States. Tob Control 1998;7:369-75.

19. O'Connor RJ, Hammond D, McNeill A, et al. How do different cigarette design features influence the standard tar yields of popular cigarette brands sold in different countries? Tob Control 2008;17:i1-5.

20. O'Connor RJ, Cummings KM, Giovino GA, et al. How did UK cigarette makers reduce tar to $10 \mathrm{mg}$ or less? BMJ 2006;332:302.

21. Stephens WE, Calder A, Newton J. Source and health implications of high toxic metal concentrations in illicit tobacco products. Environ Sci Technol 2005;39:479-88

22. Stephens WE, Calder A. Analysis of non-organic elements in plant foliage using polarized X-ray fluorescence spectrometry. Analytica Chimica Acta 2004;522 89-96.

23. Counts ME, Morton MJ, Laffoon SW, et al. Smoke composition and predicting relationships for international commercial cigarettes smoked with three machinesmoking conditions. Regul Toxicol Pharmacol 2005;41:185-227.

24. Hammond D, O'Connor RJ. Constituents in tobacco and smoke emissions from Canadian cigarettes. Tob Control 2008;17:i24-31.

25. Stephens WE. Dependence of tar, nicotine and carbon monoxide yields on physical parameters: implications for exposure, emissions control and monitoring. Tob Control 2007:16:170-6.

26. Elton-Marshall T, Fong GT, Zanna MP, et al. Beliefs about the relative harm of 'Light' and 'Low Tar' cigarettes: findings from the International Tobacco Control (ITC) China Survey. Tobacco Control 2010;19(Suppl 2):i54-i62.

27. Golia EE, Dimirkou A, Mitsios IK. Heavy-metal concentration in tobacco leaves in relation to their available soil fractions. Commun Soil Sci Plant Anal 2009; $40(1-6): 106-20$.

28. Galazyn-Sidorczuk M, Brzóska M, Moniuszko-Jakoniuk J. Estimation of polish cigarettes contamination with cadmium and lead, and exposure to these metals via smoking. Environ Monit Assess 2008;137:481-93.

29. Wu D, Landsberger S, Larson SM. Determination of the elemental distribution in cigarette components and smoke by instrumental neutron activation analysis. J Radioanal Nucl Chem 1997;217:77-82.

30. De Palma G, Goldoni M, Catalani S, et al. Metallic elements in pulmonary biopsies from lung cancer and control subjects. Acta Biomed 2008;79(Suppl. 1):43-51.

31. Fowles $\mathbf{J}$, Dybing E. Application of toxicological risk assessment principles to the chemical constituents of cigarette smoke. Tob Control 2003;12:424-36.

32. Australia New Zealand Food Standards Code. Chapter 1, Part 1.4, Standard 1.4.1: Contaminants and natural toxicants. http://www.foodstandards.gov.au/ srcfiles/Standard 141 Contaminants v109.pdf.

33. Gay G. Changing $\overline{\text { Faces- }}$ - the recent Coresta meeting in Shanghai suggests future tobacco research will increasingly be dominated by Asian scientists. Tobacco Reporter 2009 Jan:34-38. 